\title{
Beziehungen zwischen Kalium- und Kohlenhydratstoffwechselstörungen bei Diabetes Mellitus
}

\author{
Kazimierz Bojanowicz und Andrzed Zubowski
}

1. Medizinische Klinik der Medizinischen Akademic in Lódź, Polen (I)irektor: Doz. Dr. med. habil. K. Bojanowıcz)

Eingegangen am 12. August 1966

Relationships between disturbances in Potassium and carbohydrate metabolism in diabetes mellitus

Summary. The glucose tolerance was measured in 84 patients examined under controlled conditions, and related to the potassium concentration of serum, or plasma and that in erythrocytes. Forty-three obese patients were given $2 \mathrm{mg}$ of Polythiazid-Renese [Pfizer] by mouth for 7 days to promote elimination of salt. The resulting hypokaliaemia caused a reduction in glucose tolerance. This was greatest in 23 patients with diabetes mellitus, moderate in 12 patients with latent diabetes, and least in 8 obese patients with normal carbohydrate metabolism. Thirty-six hypokaliaemic patients were given a mixture of potassium acetate and potassium bromide for several days until serum potassium was normal. This brought about a return to normal of the values obtained in the glucose tolerance test. Simultaneous administration of Renese and the potassium mixture in 15 cases caused only an insignificant fall in serum potassium without any appreciable change in blood glucose. In 33 out of 36 patients with maturity-onset diabetes, the administration of the potassium mixture alone caused a noticable improvement in the glucose tolerance test and at the same time a small rise in serum potassium. In 5 normal subjects the changes were unimportant. The results obtained were statistically significant. - Conclusion: In the assessment of latent diabetes and of diabetes mellitus the role of disturbances in potassium metabolism should not be overlooked.

Rapports entre les troubles du métabolisme du potassium et des glucides dans le diabète sucré.

Résumé. Nous avons pratiqué une épreuve de tolérance au glucose sur 84 malades en état d'équilibre glucidique contrôlé, et établi des relations avec la teneur en potassium du sérum, du plasma et des globules rouges. Sur ce nombre, 43 obèses ont reçu par voie buccale $2 \mathrm{mg}$ d'un diurétique (Polythiazid-Renese, Pfizer) pendant 7 jours. L'hypokaliémie ainsi obtenue a provoqué une diminution de la tolérance au glucose; celte altération était maximale chez 23 diabétiques, moyenne chez 12 diabétiques latents et minimale chez 8 obèses sans troubles du métabolisme des glucides. 36 malades atteints d'hypokaliémie ont reçu pendant 7 à 8 jours en moyenne un mélange d'acétate de potassium et de bromure de potassium jusqu'au rétablissement de la kaliémie normale. Le test de toléran. ce au glucose a été normalisé du même coup. L'administration simultanée de Renese et d'un mélange potassique à 15 malades a provoqué un abaissement négligeable de la teneur en potassium, sans modifier sensiblement la glycómio. Dans le diabète de l'âge mur, lo mélange potassique a suffi à lui seul à amener une amélioration visible du test de tolérance au glucose, ainsi qu'une légère augmentation du taux de potassium dans le sérum chez 33 malades sur 36 . Chez 5 sujets bien portants, les modifications ont été négligeables. Les résultats obtenus sont statistiquement significatifs. - Conclusion: Dans le diagnostic du diabète latent et du diabète sucré, il faut tenir compte des effets dus aux altérations du métabolisme du potassium.

Zusammenfassung. Bei 84 Personen mit stabilem Kohlenhydratstoffwechsel wurde die Glucosetoleranz und ihre Beziehung zum Kaliumspiegel im Serum, Plasma und in Erythrocyten untersucht. Bei 43 Fettsüchtigen wurde mehrmals oral $2 \mathrm{mg}$ eines Salureticums PolythiazidRenese, Pfizer verabreicht. Die danach auftretende $\mathbf{H y -}$ pokaliämie verursachte eine Verminderung der Glucosetoleranz, die bei 23 Kranken mit Diabetes mellitus am ausgeprägsten war. Bei 12 Kranken mit latentem Diabetes wurde eine mittelstarke und bei 8 Fettsüchtigen ohne Kohlenhydratstoffwechselstörungen nur eine schwache Verschlechterung der Glucosetoleranz gefunden. 36 Patienten mit Hypokaliämie erhielten eine Kaliumacetatund Bromkaliummischung bis zur Erlangung der Normokaliämie. Daraufhin normalisierte sich die Glucosetoleranz. Die gleichzeitige Verabreichung von Renese und der Kaliummischung in 15 Fällen führte zu einer unbedeutenden Erniedrigung des Kaliumspiegels ohne wesentliche Glykämieveränderungen. Beim Altersdiabetes erreichte man nach Anwendung der Kaliummischung allein bei 33 von 36 Behandelten eine deutliche Verbesserung der Glucosetoleranz und gleichzeitig einen geringgradigen Anstieg des Kaliumspiegels im Serum. Bei 5 Gesunden waren die Veränderungen unwesentlich. Sämtliche Ergebnisse sind statistisch gesichert. - Schlußfolgerung: Bei Beurteilung des latenten Diabetes und Diabetes mellitus sollte der mögliche Einfluß einer Störung des Kaliumstoffwechsels mit in Betracht gezogen werden.

Key-words: Potassium, glucose tolerance, carbohydrate, metabolism.

\section{Literatur}

Renese (Polythiazid) ((2-methyl-3,4-dihydro-3$(2,2,2$, - trifluoroethylthiomethyl)-6 -chloro - 7 -sulfamyl 1,2,4,-benzothiadiazine 1,1 dioxide-)) (Abb.) ist ein neueres harntreibendes Arzneimittel mit starker natriuretischer Wirkung, das nach Meinung vieler

* Nach einer Mitteilung auf der II. Tagung der Europäischen Gesellschaft für Diabetologie in Aarhus am 6. 7.1966 .<smiles>CN1C(CSCC(F)(F)F)NC2=C(CC(OS(=O)(=O)O)C(Cl)C2)S1(=O)=O</smiles>

Forscher $[10,12,18,21,22,28,32]$ selten zur Hypokaliämie führt. Um die hypokaliämische Wirkung der Thiazide auszugleichen, fügen einige pharmazeutische Firmen diesem Mittel Kalium zu. Kurz nach An- 
wendung des Chlorothiazids wurde bei Zuckerkranken manchmal eine Verschlechterung der Glucosetoleranz festgestellt (WiLKINs, 1959) [29]. Diese Feststellung wurde vielmals bestätigt: GoLDNeR et al. [16], Zatuchni und Kordasz [35], Reutter und LabHaRT [24], Romero [25], Vemarajta [33]: Kokot [20] stellte fest, daß nach Renese bei Fettleibigen ofter als bei Schlanken neben der Senkung des Kaliumspiegels im Serum eine Hyperglykämie entsteht. Diese Verschlechterung der Glucosetoleranz kommt nach SAU. DAN et al. [27] nur bei Praediabetikern zustande, nach KaEDING et al. [19] und WoLFF [31] ofter bei Fettleibigen. Christen und Siegrexthater [8] hoben hervor, daß diese Störung reversibel ist. FormaneK [13] bemerkte, daß es bei Tieren unter dem Einfluß der Thiazide zu einer Abschwächung der Insulinaktivität kommt. Dollery et al. [11] sind der Ansicht, daß die Störungen des Kohlenhydratstoffwechsels die Folge einer reversiblen Schädigung der Langerhansinseln und einer Verringerung der Insulinsekretion sind. RAPOPORT und HURD [23] haben auf die Rolle der Hypokaliämie in Fällen, wo die Thiazide eine Hyperglykämie hervorriefen, hingewiesen. WoLFF und ParMLey [30] fanden an Tieren, daß Chlorkalium mit Benzothiazid zusammen angewendet, das Auftreten der Hyperglykämie verhütet. VerRov und DUDLEY [34] haben bei Menschen bemerkt, daß die hyperglykämische Wirkung öfter nach Thiaziden allein, als nach Thiaziden mit Kaliumzusatz festzustellen ist. GARDNER et al. [15] sowie FuHrman [14] schildern bei Ratten die Abhängigkeit zwischen Hypokaliämie und Verminderung der Glucosetoleranz. Andere Untersuchungen an Ratten haben keine besonderen Änderungen des Blutzuckerspiegels nach Polythiaziden aufgewiesen [18]. SAGILD et al. [26] konnten bei Menschen mit Hilfe von harzhaltigen Austauschern eine Hypokaliämie hervorrufen und erreichten ebenfalls eine Verschlechterung der Glucosetoleranz, die sie als Folge einer verminderten Insulinproduktion ansahen. KAEDING und Schwarz [19] sind dagegen der Ansicht, daß zwischen den Störungen des Kohlenhydratstoffwechsels und der Hypokaliämie nach Thiaziden keine Abhängigkeit besteht. Schon im Jahre 1950 hat BoJAnowicz [1] bewiesen, daß Kaliumazetat bei Hochdruckkranken mit Hyperglykämie den Zuckerspiegel im Blute senkt, indem es die Tätigkeit der Nebennierenrinde hemmt. Seine weiteren Untersuchungen (1953-1961) $[2,4,5]$, brachten neue Beweise für die hypoglykämische Wirkung des Kaliums. Im Jahre 1960 stellte BoJano. wICz [3] den hypoglykämischen Einfluß der Kalium. azetat- und Bromkaliummischung bei Altersdiabetes fest. BoJanowicz und ZUBOwskr haben im Jahre 1965 [6] gezeigt, daß diese Mischung auf die verringerte Glucosetoleranz nach Polythiazid einen normalisierenden Einfluß ausübt. Auch Cons [9] stellte fest (1965), daß beim primären Hyperaldosteronismus der diabetische Typ der Blutzuckerkurve nach einer Kaliumdarreichung zur Normalisierung kommt, ähnlich wie nach Beseitigung des Nebennierenrindenadenoms. Er ist der Ansicht, daß infolge des örtlichen Kaliummangels eine reversible biochemische Schädigung der Beta-Zellen der Bauchspeicheldrüse entsteht. Kaliumanwendung vergrößert die Fähigkeit dieser Zellen zur Insulinerzeugung, was eine Normalisierung der Blutzuckerkurve bewirkt. BOJANOWICZ, ZUBOWSKI und Patora [7] haben im Jahre 1966 eine reversible Abhängigkeit zwischen den Kohlenhydrat- und Kaliumstoffwechselstörungen festgestellt, deswegen konnte Kalium zur Behandlung des Diabetes verwendet werden. Grodsky [17] hat diesen Standpunkt mit Untersuchungen bei Tieren bestätigt: die Steigerung der Insulinproduktion war proportional zur Konzentration des Kaliums, das zur Spülung der Bauchspeicheldrüse verwendet wurde.

\section{Eigene Untersuchungen}

Wir haben Beziehungen zwischen Schwankungen des Kaliumspiegels im Blut, im Serum oder Plasma, und in den roten Blutkörperchen; und der Glucosetoleranz untersucht: a) bei Hypokaliämie nach Verabreichung eines Salureticums-Polythiazid ,RenesePfizer"; b) nach Ausgleichung des Kaliumdefizites mittels nachfolgender Zufuhr der Kaliummischung: Sol. Liq. Kalii acetici e 20.0-180.0; Kalii bromati 10.0. MDS. 5 mal täglich ein Eßlöffel, c) bei der teilweise erreichten Vorbeugung der Hypokaliämie durch die gemeinsame Verordnung von Polythiazid und Kaliummischung: d) bei genügender Kaliumzufuhr - manchmal bei leichter Hyperkaliämie - als Folge der Behandlung des Diabetes mellitus mit der Kaliummischung.

Es wurden insgesamt 84 Personen untersucht, nämlich 71 Kranke mit Kohlenhydratstoffwechselstörungen - darunter 59 Fettleibige mit Altersdiabetes, 12 Fettleibige mit latentem Diabetes - und 13 Personen ohne Kohlenhydratstoffwechselstörungen - darunter 8 Fettleibige und 5 Gesunde. Es handelte sich um 67 Frauen und 17 Männer, im Alter von 23 bis 69 Jahren, durchschnittlich 53 Jahre. Bei den Fettleibigen betrug das Übergewicht $+11 \%$ bis $+65 \%$, durchschnittlich $+29.7 \%$. Die Untersuchungen wurden bei Stabilisation des Kohlenhydratstoffwechsels durchgeführt, d.h. bei ständiger Diät und ständiger Insulin- oder Tablettendosis und nach Ausgleichung bedeutender Harn- und Blutzuckerschwankungen. Bei der Bewertung der Glucosetoleranz hat sich besonders die sogenannte Glykämiegesamtsumme nach BoJAnowICZ bewährt, das heißt die Summe der 6 Werte des Glucosespiegels im Blut nach Belastung mit $50 \mathrm{G}$. Glucose.

a) Es wurde 43 Fettleibigen das SalureticumPolythiazid „Renese-Pfizer" $2 \mathrm{mg}$ per os täglich, durchschnittlich 7.1 Tage lang verabreicht. Darunter waren 23 Kranke mit Diabetes mellitus, 12 Personen mit latentem Diabetes und 8 ohne Kohlenhydratstoffwechselstörung, 37 Frauen und 6 Männer, im Alter von 23 bis 69 Jahre, durchschnittlich 52 Jahre, 
mit einem Übergewicht von $+11 \%$ bis $+65 \%$, durchschnittlich $+26.9 \%$. Bei 31 Personen (15 Diabetikern, 10 mit latentem Diabetes und 6 Fettleibigen ohne Kohlenhydratstoffwechselstörung) wurde der Kaliumspiegel im Serum untersucht. Er sank bei 29 Personen

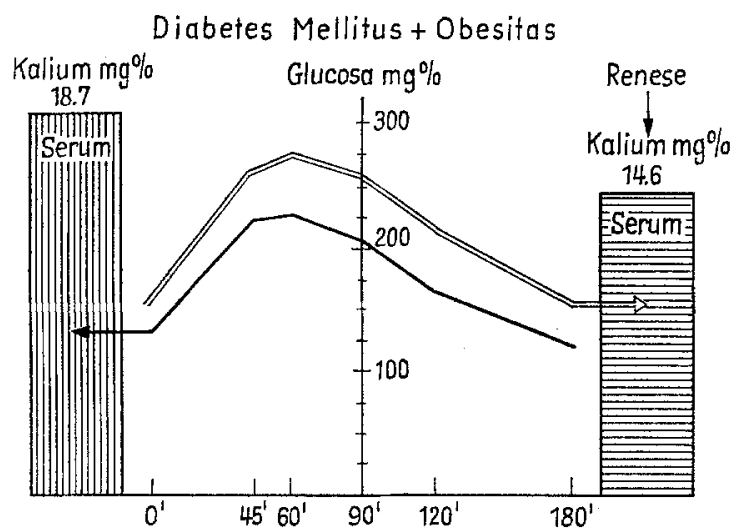

Abb. 1 u. 3. Steigerung der Glykämie als Folge der Hypokaliämie im Serum und in den roten Blutkörperchen

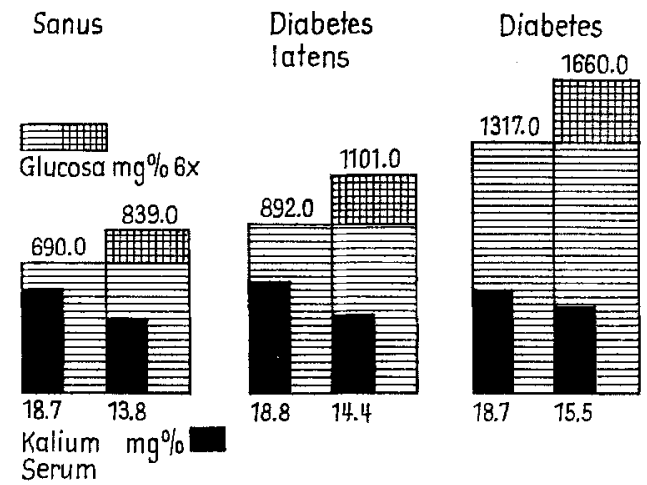

Abb. 2. Verminderung der Glykosetoleranz als Folge der Hypokaliämie bei latentem Diabetes und besonders bei Diabetes mellitus

Diabetes Mellitus + Obesitas

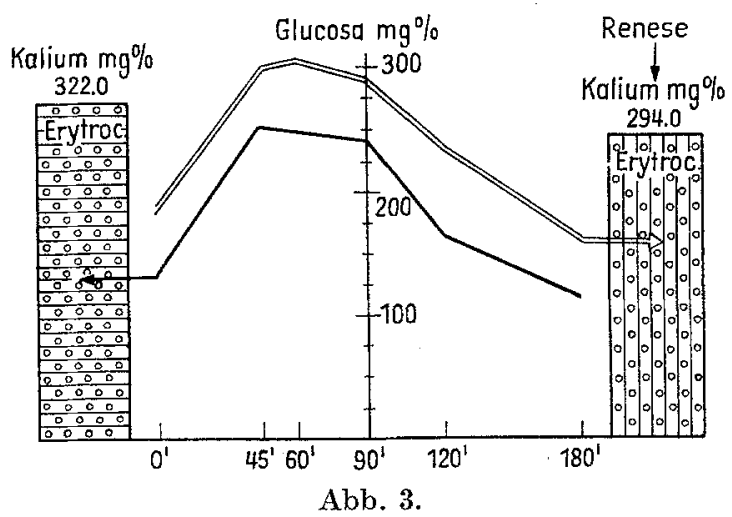

durchschnittlich um $4.1 \mathrm{mg} \%(1.05 \mathrm{~m} \mathrm{val} / \mathrm{l})(p=0.05$, $t=14.64)$. Gleichzeitig stieg bei 26 Personen die Glykämiegesamtsumme durchschnittlich um $275 \mathrm{mg} \%$ $(p=0.05, t=8.33)$ (Abb. 1). In einem Fall sank die Glykämie bei gleichzeitigem Anstieg des Kalium- spiegels, bei 4 Personen fanden wir atypische Verhältnisse.

Bei Diabetes mellitus verursachte die kleinste Hypokaliämie $(15.5 \mathrm{mg} \%=3.98 \mathrm{~m}$ val $/ 1)$ den größten Anstieg der Glykämiegesamtsumme (durchschnittlich um $343 \mathrm{mg} \%$ ), bei latentem Diabetes - die mittlere Hypokaliämie $(14.4 \mathrm{mg} \%=3.70 \mathrm{~m}$ val $/ \mathrm{l})$ den mittleren Anstieg der Glykämiegesamtsumme (durchschnittlich um $269 \mathrm{mg} \%$ ), bei Personen ohne Kohlenhydratstoffwechselstörungen rief die größte Hypokaliämie (13.8 $\mathrm{mg} \%=3.55 \mathrm{~m} \mathrm{val} / \mathrm{l}$ ) den kleinsten Anstieg der Glykämiegesamtsumme hervor (durchschnittlich um $149 \mathrm{mg} \%$ ). Die Untersuchungen haben also die größte Empfindlichkeit gegen Hypokaliämie bei Diabetes mellitus ergeben. Das Ergebnis war statistisch signifikant $(p=0.05)$ : zwischen Diabetes mellitus und Personen ohne Kohlenhydratstoffwechselstörung betrug $t=2.16$ für den Unterschied in der Erhöhung der Glykämiegesamtsumme, und $t=3.43$ für den Unterschied in der Kaliumsenkung (Abb. 2).

Bei weiteren 12 Fettleibigen (darunter 8 mit Dia. betes mellitus, 2 mit latentem Diabetes und 2 ohne Kohlenhydratstoffwechselstörungen) wurde der Kaliumspiegel im Plasma und in den roten Blutkörperchen bestimmt. Die oben beschriebenen typischen Beziehungen zwischen dem Kalium- und Kohlenhydratstoffwechsel fanden wir im Plasma bei 10 Personen (Kaliumsenkung um $3.6 \mathrm{mg} \%=0.92 \mathrm{~m} \mathrm{val} / \mathrm{l}$ ) und Steigerung der Glykämiegesamtsumme um $316 \mathrm{mg} \%$, in den roten Blutkörperchen dagegen nur bei 6 Personen (Kaliumsenkung durchschnittlich um $28 \mathrm{mg} \%$ $=7.19 \mathrm{~m} \mathrm{val} / 1$ und Steigerung der Glykämiegesamtsumme durchschnittlich um $322 \mathrm{mg} \%$ (Abb. 3).

Demzufolge stellt man zwischen den Glykämie- und Kaliumstörungen im Serum und Plasma die typischen Beziehungen bei $86 \%$ der Untersuchten fest. Die Hypokaliämie war die Folge einer festgestellten Kaliumdiurese.

b) Den 36 Personen, bei denen Renese eine Hypokaliämie hervorgerufen hatte, wurde die Kaliummischung durchschnittlich durch 8.7 Tage verabreicht bis zur Erlangung der Normokaliämie. Der Kaliumspiegel stieg bei 35 Personen durchschnittlich im Serum um $3.7 \mathrm{mg} \%=0.95 \mathrm{~m} \mathrm{val} / \mathrm{I}(p=0.05, t=12.72)$ (Abb. 4) und im Plasma um $5.1 \mathrm{mg} \%=1.31 \mathrm{~m} \mathrm{val} / 1$ (bei einer Person sank er weiter).

Bei 9 Personen unter 10 Untersuchten stieg der Kaliumspiegel in den roten Blutkörperchen durchsehnittlich um $29 \mathrm{mg} \%$ (Abb. 5). Gleichzeitig sank die Glykämiegesamtsumme bei 32 Personen durchschnittlich um $253 \mathrm{mg} \%(p=0.05, t=10.11)$. Die Ergebnisse waren also statistisch signifikant.

Es ist bemerkenswert, daß bei 6 Personen, bei denen es im vorigen Versuch zur Kaliumsenkung in den roten Blutkörperchen kam, der Kaliumspiegel durchschnittlich um $36 \mathrm{mg} \%=9,25 \mathrm{~m}$ val/l stieg und die Glykämiegesamtsumme durchschnittlich um 184 mg\% absank. Dagegen stieg bei 4 Personen, bei denen es im vorigen Experiment zum Kaliumanstieg in den 
roten Blutkörperchen kam, der Kaliumspiegel weiter durchschnittlich um $16 \mathrm{mg} \%$ and parallel sank die Glykämiegesamtsumme durchschnittlich sogar um $438 \mathrm{mg} \%$.

c) Bei 15 Personen wurde nach den vorigen Versuchen ( $a$ und $b$ ) gemeinsam Polythiazid und die Kaliummischung in obiger Weise verordnet. Dabei kam es nur zu einer geringen Senkung des Kaliumspiegels im Serum und im Plasma, bei allen Personen durchschnittlich um $1.8 \mathrm{mg} \%=0.46 \mathrm{~m} \mathrm{val} / 1(p=0.05$, $t=7.43$ ) (statt um $4.0 \mathrm{mg} \%=1.02 \mathrm{~m} \mathrm{val} / 1 \mathrm{nach}$ Renese allein) (Abb. 6).
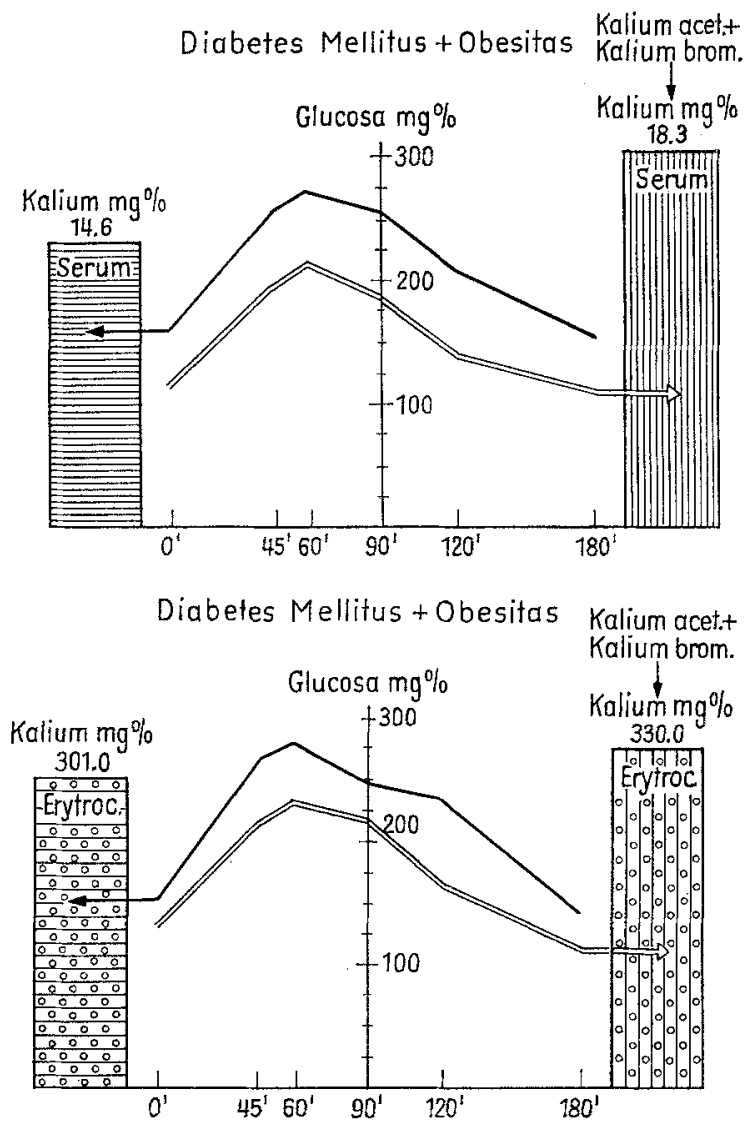

Abb. 4 u. 5. Besserung der Glykosetoleranz nach Ausgleichung des Kaliumdefizites nach der Zufuhr der Kaliummischung

Bei 6 Personen, bei denen der Kaliumspiegel in den roten Blutkörperchen untersucht wurde, kam es $\mathrm{zu}$ keinen bedeutenden Veränderungen (Abb. 7). Gleichzeitig stieg die Glykämiegesamtsumme unbedeutend (durchschnittlich um $69 \mathrm{mg} \%, p=0.05$, $t=4.81$ ) bei 13 Personen von 15 Untersuchten.

Der Unterschied zwischen den Ergebnissen des Versuches a (und c) zeigt, daß die Kaliummischung vor Kohlenhydratstoffwechselstörungen bei der Behandlung mit Renese genügend schützt.

d) Bei anderen 41 Personen wurde nur die Kaliummischung durch 14-21 Tage verordnet. Darunter waren 5 Gesunde und 36 Personen mit Altersdiabetes
(27 Frauen und 9 Männer, im Alter von 39 bis 66 Jahre durchschnittlich 54.2 Jahre, mit Übergewicht von 18 bis $62 \%$, durchschnittlich $32.4 \%$ ). Der Kaliumspiegel im Serum stieg durchschnittlich um $4.2 \mathrm{mg} \%=$

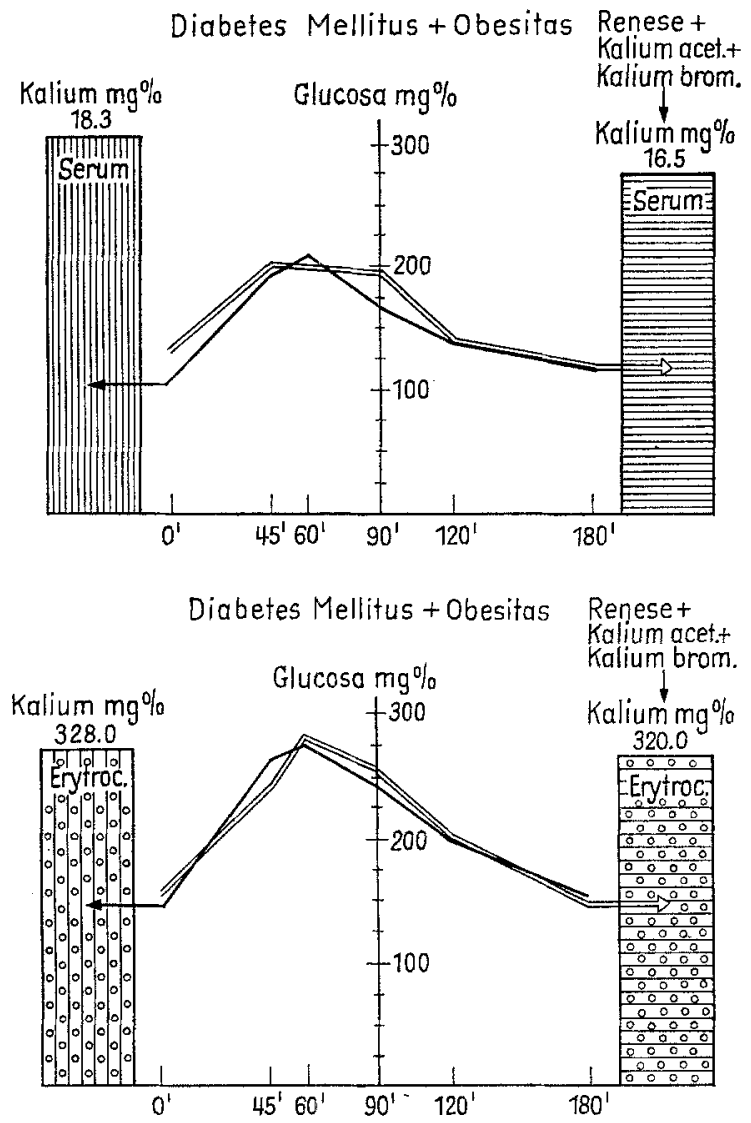

Abb. 6 u. 7. Unbedeutende Senkung des Kaliumspiegels im Serum und in den roten Blutkörperchen und parallel unbedeutende Veränderungen der Glykämie bei gemeinsamer Darreichung von Renese und der Kaliummischung

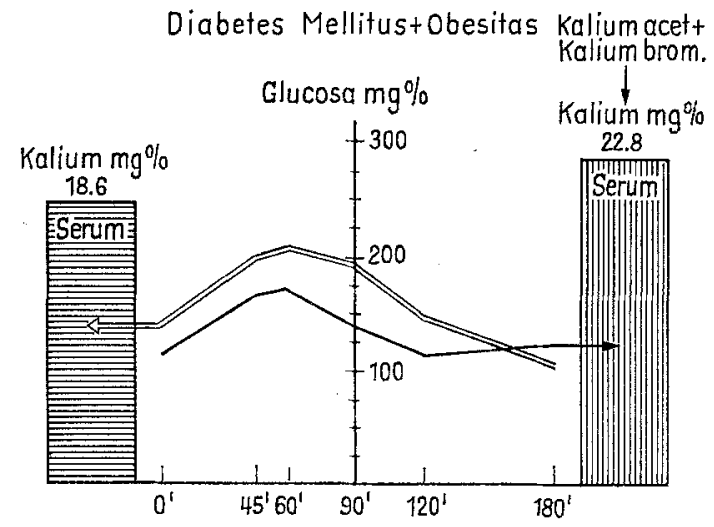

Abb. 8. Besserung der Glykosetoleranz nach Gabe der Kaliummischung bei Diabetes mellitus

$1.07 \mathrm{~m} \mathrm{val} / 1(p=0.05, t=12.32)$, gleichzeitig sank die Glykämiegesamtsumme bei 33 von 36 Personen mit Altersdiabetes durchschnittlich um $154 \mathrm{mg} \%(p=0,05$, 
$t=6.28)(\mathrm{Abb} .8)$, bei 3 Kranken kam es zu einem Anstieg der Glykämie. Die Ergebnisse waren also statistisch signifikant. Bei 5 Gesunden fanden wir keine wesentlichen Veränderungen in der Glykämie.

\section{Diskussion}

Die bei Anwendung von Thiaziden festgestellten Störungen des Kalium- und Kohlenhydratstoffwechsels wurden bisher meistens unabhängig voneinander als Nebenwirkung dieser Arzneimittel angesehen. Nur einzelne Forscher schreiben dem Kalium eine Rolle in der Regulation des Kohlenhydratstoffwechsels zu. Wir fanden aber in der uns zugänglichen Literatur keine Aussagen über deren Anwendungsmöglichkeiten in der Behandlung des Diabetes. Unsere Untersuchungen haben gezeigt, daß die Störungen des Kohlenhydratstoffwechsels nach Verabreichung von Kalium nicht nur umkehrbar, sondern auch vom Kaliummangel abhängig sein können. Es muß dabei bemerkt werden, daß der Kaliummangel aus verschiedenen Gründen entstehen kann, außerdem soll nicht nur der Einfluß des Kaliums auf die Insulinproduktion in Betracht gezogen werden, auch seine Fähigkeit zur Hemmung der Nebennierenrinde $\mathrm{muß}$ berücksichtigt werden (BoJANowIoz, 1950). Es ist möglich, daß Kalium auf diese Weise die Anzahl der Insulininaktivatoren verringert. Aus unseren Untersuchungen geht hervor, daß wahrscheinlich eine neue iatrogene Diabetesform, ein Kaliummangel-Diabetes, zu unterscheiden sein könnte. Es ist aber auch möglich, daß ein Kaliummangel nicht iatrogener Herkunft eine größere Rolle beim Altersdiabetes spielt, als es bisher angenommen wurde. In der Literatur wird dieses Problem bisher fast ausschließlich auf Grund der Untersuchungen der Elektrolyte im Plasma beurteilt. Unsere Forschungen unterstreichen die große Wichtigkeit der Bestimmungen der Elektrolyte in den roten Blutkörperchen, da diese besser die Störungen des Elektrolytstoffwechsels im Körper zu bewerten erlauben. Wir wollen außerdem darauf hinweisen, daß Kalium ein wichtiges Hilfsmittel bei der Behandlung des Altersdiabetes sein kann. Wir empfehlen als besonders wirksam die Mischung von Kaliumazetat und Bromkalium und kaliumreiche Speisen, wie Fleisch, Gemüse, Obst und Kartoffeln, deren Menge genauso ausgemessen sein sollte, wie die der Kohlenhydrate, der Fette, des Eiweißes und der Vitamine. Abweichungen in den Ergebnissen einzelner Forscher könnten von verschiedener Anzahl eingenommener kaliumreicher Speisen abhängig sein, die der Gewohnheit verschiedener Nationen entsprechen.

\section{Schlußfolgerungen}

a) Es wurden statistisch signifikante Beziehungen zwischen Kalium- und Kohlenhydratstoffwechselstörungen bei Kranken mit Altersdiabetes festgestellt: Hypokaliämie führte zum Anstieg der Glykämie, Steigerung des Kaliumspiegels zur Senkung der
Glykämie. Die Beziehungen sind schon beim latenten Diabetes (aber geringer) angedeutet.

b) Bei der Beurteilung der Blutzuckerbelastungskurve und der Diagnose des Diabetes mellitus bzw. des latenten Diabetes sollte der Kaliumspiegel wenigstens im Serum berücksichtigt werden. Bei vorhandener Hypokaliämie sollte diese zuerst vor Behandlung der Kohlenhydratstoffwechselstörungen beseitigt werden, die in solchen Fällen mit Kaliumzufuhr allein umkehrbar sind.

c) Die besondere Empfindlichkeit des Altersdiabetes auf Hypokaliämie kann vom Kaliumdefizit abhängig sein, deshalb scheint in der Behandlung und Vorbeugung des Diabetes mellitus und des latenten Diabetes eine genügende Kaliumzufuhr in pharmakologischer oder diätetischer Form wichtig zu sein.

d) Bei Behandlung der Kreislaufstörungen und Hypertonie der Zuckerkranken mit saluretischen Mitteln muß für genügende Kaliumzufuhr gesorgt werden.

\section{Literatur}

[1] Bojanowicz, K.: Próby leczenia nadciśnienia krwi podawaniem octanu potasu, jako metoda hamująca nadczynność kory nadnerczy. Przegl. lek. 17, 609$612(1950)$

[2] - Ambulatoryjne leczenie zespołu nadciśnienia octanem i bromkiem potasu. Pol. Tyg. lek. 52, $1758-1763$ (1953).

[3] - Badania nad wpływem mieszanki octanu i bromku potasu na krzywa cukru we krwi w chorobie nadciśnieniowej i u chorych z cukrzyca. Pol. Tyg. lek. 11, 414-416 (1960).

[4] - Badania nad działaniem octanu i bromku potasu w chorobie nadciśnieniowej. Lódzkie Towąrzystwo Naukowe. Wydział IV, 30 (1961).

[5] - Drogi leczniczego dzialania octanu i bromku potasu $w$ chorobie nadciśnieniowej. Pol. Arch. Med. wewnęt. 3, 319-325 (1962).

[6] -, und A. ZuвоwsкI: Experimentelle Untersuchungen und Behandlung des Diabetes mellitus mit Kaliumacetat- und Bromkaliummischung. Diabetologia 2, $138(1965)$.

[7] -, A. ZuBowskr und T. Patora: Beziehungen zwischen Kalium- und Kohlenhydratstoffwechselstörungen bei Diabetes mellitus. Diabetologia 2, 141 (1966).

[8] Christen, Ph., und W. Stegentrhaler: Saluretika und Kohlenhydratstoffwechsel. Praxis 5, 152-156 (1964).

[9] Cons, J.W.: Hypertension, the potassium ion and impaired carbohydrate tolerance. New Engl. J. 21, $1135-1143$ (1965).

[10] Dмосноwsкr, St.r und H. Rficiga: Polithiazydnowy, skuteczny środek moczopedny. Annales Acad. Med. Lodzensis. VII. 113-122 (1966).

[11] Dollery, C.T., B.L. Pentecost and N.A. Samaan, Drug-induced diabetes. Lancet 1962 II, 735-737.

[12] FoRD, R.V.: Clinical pharmacologic investigation of polythiazide a potent oral diuretic agent. Curr. Ther. Res. 3, 320-328 (1961).

[13] FormanEk, K.: Zur Beeinflussung der Blutzuckerregulation durch Dihydrochlorothiazid. Wien. klin. Wschr. 75, $211-213$ (1963).

[14] Funrmar, F.A.: Glycogen, glucose tolerance, and tissue metabolism in potassium-deficient rats. Amer. J. Physiol. 167, 314-320 (1951).

[15] Gardner, L.I., W.B. Talbot, C.D. Cook, H. Ber- 
MAN and C. URIBE: The effect of potassium deficiency on carbohydrate metabolism. J. Lab. clin. Med. 35, $592-602(1950)$.

[16] Goldner, M.G., H. Zarowitz and S. Akgun: Hyperglycemia and glycosuria due the thiazide derivatives administered in diabetes mellitus. New Engl. J. Med. 262, 403-405 (1960).

[17] GRodsky : Äußerung während der II. Sitzung der Europäischen Gesellschaft für Diabetologie. Aarhus 1966.

[18] Initial Laboratory and Clinical Reports. Renese (polythiazide-P.2525) Medical Department Pfizer Intern. Inc. New York 1962.

[19] Kanding, A., und F. Schwarz: Alimentäre Hyperglykämie und Saluretika. Z. ges. inn. Med. 20, 149153 (1965).

[20] Kокот, F.: Zmiany biochemiczne we krwi po stosowaniu renezy u ludzi otyłych i nieotyłych. Pol. Arch. Med. wewnęt. 4, 401-405 (1966).

[21] KościóєeK, A.: Działanie moczopędne leku Renese. Wiad. lek. 5, 379-383 (1964).

[22] Mandecki, T.: Moczopedne i hipotensyjne działanie preparatu „Renese“ Przegl. lek. 6, 303-306 (1964).

[23] Rapoport, M., and H. HuRd: Thiazide-induced glucose intolerance treated with potassium. Arch. intern. Med. 113, 405-408 (1964).

[24] Reutter, F., und A. LabHart: Saluretica und Glucosetoleranz. Helv. med. Acta 28, 487-495 (1961).

[25] Romero, E.: Diabetogenic action of saluretics. Rev. clin. esp., 97, 302-307 (1965).

[26] Sagild, U., V. ANDERsen and P.B. ANDreasen:
Glucose tolerance and insulin responsiveness in experimental potassium depletion. Acta med. scand. 169, 243-251 (1961).

[27] SaUdan, Y., D. Masson and B. Curchod: L'ìnfluence des salidiuretiques sur la régulation de la glycémie Praxis 3, 45-48 (1961).

[28] TAPIA, F.A.: Diuretic and antihypertensive affects of polythiazide. Curr. Ther. Res. 3, 365-377 (1961).

[29] WILkins, R.W.: New drugs for the treatment of hypertension. Ann. Int. Med. 50, 1-10 (1959).

[30] WolfF, F.W., and W.W. Parmuey: Etiological factors in benzothiadiazine hyperglycemia. Lancet $1963 \mathrm{II}, 69$.

[31] - Clinical and physiological implications of diabetes induced by benzothiadiazines. Diabetes 2, 203-205 (1964).

[32] Woytok, J., and K. JAcyszyn : Zastosowanie Renese w leczeniu obrzęków u. kobiet ciężarnych. Pol. Tyg. lek. 13, 476-477 (1965).

[33] Veharanta, T.: Thiazide diuretics as diabetogenic agents. Suom. Lääk.-L. 19, 1569-75 (1964).

[34] Verbov, J.L., and N.E. Dudley: Some Problems of Thiazide Diuretic Therapy. Brit. J. 19, 29-31 (1965).

[35] Zatuchni, J., and F. Kondasz: The diabetogenic effect of thiazide diuretics. Amer. J. Cardiol. 7, 565567 (1961).

Doz. Dr. med. habil. KazimuzRz BojaNowicz ul. Rewolucji 1905 r. nr. $76 \mathrm{~m} .1$ Eódź-Polen 